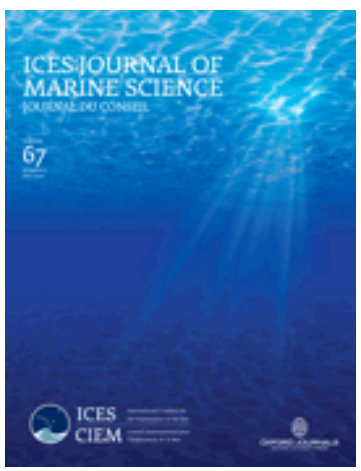

\title{
Prediction of square mesh panel and codend size selectivity of blue whiting based on fish morphology
}

\begin{tabular}{|c|c|}
\hline Journal: & ICES Journal of Marine Science \\
\hline Manuscript ID & ICESJMS-2020-322.R2 \\
\hline Manuscript Types: & Original Article \\
\hline $\begin{array}{l}\text { Date Submitted by the } \\
\text { Author: }\end{array}$ & 06-Aug-2020 \\
\hline Complete List of Authors: & $\begin{array}{l}\text { Cuende, Elsa; AZTI (BRTA), Marine Research Division } \\
\text { Arregi, Luis; AZTI (BRTA), Marine Research Division } \\
\text { Herrmann, Bent; SINTEF Fisheries and Aquaculture, Fishing Gear } \\
\text { Technology } \\
\text { Sistiaga, Manu; Institute of Marine Research, Fisheries Technology } \\
\text { Aboitiz, Xabier; AZTI (BRTA), Marine Research Division }\end{array}$ \\
\hline Keyword: & $\begin{array}{l}\text { Square mesh panel (SMP), opening angle, Micromesistius poutassou, fish } \\
\text { behaviour, contact angle }\end{array}$ \\
\hline
\end{tabular}

\section{SCHOLARONE Manuscripts}




\section{Prediction of square mesh panel and codend size 2 selectivity of blue whiting based on fish morphology}

3 Elsa Cuende ${ }^{1 * \diamond}$, Luis Arregi ${ }^{1}$, , Bent Herrmann ${ }^{2 \diamond}$, Manu Sistiaga ${ }^{3 \diamond}$, Xabier Aboitiz $^{1}$

$4 \quad{ }^{1}$ AZTI, Marine Research, Basque Research and Technology Alliance (BRTA). Txatxarramendi ugartea z/g, 548395 Sukarrieta, Bizkaia.

$6 \quad{ }^{2}$ SINTEF Ocean, Fishing Gear Technology, Willemoesvej 2, 9850, Hirtshals, Denmark; The Arctic

7 University of Norway, UiT, Breivika, N-9037 Tromsø, Norway.

8 Institute of Marine Research, Postboks 1870 Nordnes, Bergen, 5817, Norway;

9 Norwegian University of Science and technology, Otto Nielsens veg 10, N-7491 Trondheim, Norway.

*Corresponding author: AZTI, Marine Research, Basque Research and Technology Alliance (BRTA). 


\section{Abstract}

17 Square mesh panels (SMPs) are selective devices used extensively to supplement codend size selectivity in 18 trawl fisheries. Therefore, predictions of the effect of mesh size in both SMPs and codends on size 19 selectivity are valuable. Here, we established a framework to predict size selection of blue whiting through 20 different SMPs and diamond mesh codends based on the morphological characteristics of this species. We 21 hypothesized that size selection for a SMP is determined by different fish contact angles, whereas different 22 mesh opening angles determine size selection for the codend. Based on these hypotheses, we first developed 23 a model that enabled us to predict which sizes of blue whiting are able to pass through meshes of different 24 sizes and shapes. We then tested whether the selectivity for blue whiting of the SMP, the codend, and the 25 combination of both could be explained by the models. Finally, we predicted size selectivity of multiple 26 combinations of SMPs and diamond mesh codends. The method presented here can potentially be applied 27 to make predictions for species other than blue whiting.

28 Keywords: Square mesh panel (SMP); contact angle; opening angle; fish behaviour; Micromesistius poutassou 
In many bottom trawl fisheries around the world, codend size selectivity is supplemented with additional devices such as square mesh panels (SMPs) (Özbilgin et al., 2005; Graham, 2010; STECF, 2012). Unlike in the codend, where the shape of the meshes can vary substantially (Robertson and Stewart, 1988; Herrmann, 2005a; Herrmann and O'Neill, 2005), SMPs maintain their shape and therefore provide mesh shapes that better support escape for non-targeted fish. SMPs were first introduced into legislation in the Northern European Nephrops fishery in 1992, primarily to improve the release of undersized gadoids (Merlangius merlangus) (Briggs, 1992). Since then, they have been introduced in some other crustacean (Broadhurst, 2000; Catchpole and Revill, 2007) and fish-directed fisheries (Regulation EU 2019/1241). Today, SMPs are compulsory when targeting specific species in some fishing areas (Regulation EU 2019/1241), and their applicability and efficiency have been broadly studied (O'Neill et al., 2006; Herrmann et al., 2015; Brčić et al., 2016, 2018).

Two conditions must be met for a fish to be able to escape through a SMP: the fish first needs to contact the SMP and then it needs to be able to pass through the meshes in the SMP (Herrmann et al., 2009; Sistiaga et al., 2011). A number of researchers have estimated contact probability and fish release efficiency of SMPs (e.g., Zuur et al., 2001; O’Neill et al., 2006; Herrmann et al., 2015; Santos et al., 2016; Krag et al., 2017; Sistiaga et al., 2017; Brčić et al., 2018), and some have tried to improve this contact probability to increase SMP release efficiency (Cuende et al., 2020a; Cuende et al., 2020b). In addition to having estimated the contact probability of fish with the SMP, all of these studies investigated the size selectivity of those fish that contacted it. This size selectivity is quantified in terms of L50 (length of fish that has a $50 \%$ chance of retention by the SMP assuming that contacts occurs) and selection range (SR) (= L75 - L25) (Wileman et al., 1996; Millar and Fryer, 1999; Sistiaga et al., 2010). However, when the experimentally obtained L50 and SR results are compared with the expected values based on fish morphology and SMP mesh size, the experimental L50s often are much smaller and the SRs much larger than the expected values (Alzorriz et al., 2016). No study to date has investigated in detail the reasons for this difference between the expected and obtained selectivity results.

The overall size selectivity of the gear is determined not only by the properties of the SMP but also by the size selectivity of the codend used. The factors affecting diamond mesh codend size selectivity have been 


\section{$84 \quad$ Materials and methods} properties of the gear for this species.

1996; Herrmann, 2005b), netting orientation and twine thickness (Herrmann et al., 2013a), or the number of meshes in the circumference (Sala and Lucchetti, 2011) can affect codend size selectivity because they can alter codend shape and thereby mesh shape and opening angles (OAs) (e.g., O'Neill and Herrmann, 2007; Herrmann et al., 2009; Sistiaga et al., 2011; Herrmann et al., 2012; Herrmann et al., 2013b; Tokaç et al., 2016, 2018). Several studies investigated the influence of fish morphology on codend size selectivity. However, no study has investigated the influence of fish morphology and mesh size on the overall size selectivity of a gear composed of a SMP together with a size selective codend.

Blue whiting (Micromesistius poutassou) is a globally important commercial fish species (FAO, 2018), with catches that, for example, exceeded 1.7 million tons in the Northeast Atlantic in 2018. However, little is known about its size selection in the commercial fishing gear. This species is mostly harvested with pelagic trawls, but its size selectivity is also relevant for bottom trawls, where it is discarded both in crustacean (e.g., Monteiro et al., 2001) and fish-directed mixed bottom trawl fisheries (Rochet et al., 2014). In the Basque bottom trawl fishery, mostly targeting anglerfish (Lophius spp.), megrim (Lepidorhombus spp.) and hake (Merluccius merluccius), blue whiting constitutes one of the main discarded species. In 2006, a gear composed of a $100 \mathrm{~mm}$ SMP inserted in the upper panel of the extension piece of the trawl and a $70 \mathrm{~mm}$ diamond mesh codend was introduced as a regulation in this fishery (Regulation EC 51/2006) to increase the release efficiency of undersized fish. However, Rochet et al. (2014) estimated that during the period $2011-2013 \sim 98 \%$ of the blue whiting caught in this fishery was discarded. The gear used by the fleet today is still the same and despite the Landing Obligation (Regulation EU 1380/2013) discards of blue whiting are still likely. More recently, Cuende et al. (2020a) showed that a considerable percentage of the blue whiting entering the gear was able to contact the SMP, meaning that a properly designed SMP would substantially affect the overall trawl size selection. For these reasons, blue whiting is a relevant species to investigate the size selectivity of a trawl equipped with a SMP and a diamond mesh codend.

The goals of this study were to investigate size selection of blue whiting through SMPs and diamond mesh codends and to predict the effect of SMP and codend mesh size and shape on the overall size selective

In the past, size selectivity studies of towed fishing gears have mainly been carried out at sea following a trial and error procedure (Kvamme and Isaksen, 2004; Jørgensen et al., 2006). However, as sea trials are 
costly and time consuming, modelling, and predictive work have become more common in this field to supplement and assist experimental methods (Herrmann, 2005b; Herrmann et al., 2009).

In this study, we applied a three-step approach to predict size selection of blue whiting for different combinations of SMP and codend mesh sizes:

1. We developed a model that enabled us to predict which sizes of blue whiting are able to pass through meshes of different sizes and shapes. To do this, we used FISHSELECT, which is a framework of tools, methods, and software developed to determine whether or not a fish is able to penetrate a certain mesh by comparing the morphology of the fish and the geometry of the mesh. The methodology was previously used to investigate size selectivity for numerous species in various fisheries (Frandsen et al., 2010; Sistiaga et al., 2011; Krag et al., 2011; Herrmann et al., 2012, Herrmann et al., 2013b; Krag et al., 2014; Herrmann et al., 2016; Tokaç et al., 2016). It was applied to blue whiting for the first time in our study.

2. Based on selectivity results obtained from sea trials carried out with a gear configuration composed of a SMP and a diamond mesh codend (Cuende et al., 2020a), we tested whether the selectivity for blue whiting of the SMP, the codend, and the combination of both could be explained by the models obtained from the application of FISHSELECT.

3. Provided that the experimental results obtained at sea (Cuende et al., 2020a) could be explained by the models obtained from the application of FISHSELECT, we predicted the size selectivity of multiple combinations of SMPs and diamond mesh codends.

\section{Collection of morphology and mesh penetrability data of blue whiting using FISHSELECT}

In October 2016, blue whiting individuals were collected onboard the pair-trawler "Aketxe-Gaztelugatxe" (26 m length overall; $270 \mathrm{HP}$ ) in the Bay of Biscay (ICES subdivision VIIIc) between $43^{\circ} 24^{\prime} \mathrm{N}-43^{\circ} 30^{\prime} \mathrm{N}$ and $1^{\circ} 48^{\prime} \mathrm{W}-2^{\circ} 21^{\prime} \mathrm{W}$. A total of 55 blue whiting ranging from 14 to $32 \mathrm{~cm}$ in length were selected with all length classes being represented randomly with one to five individuals. FISHSELECT requires precise measuring of fish morphology, and it is important that the shape of the fish measured is not affected by dehydration, depressurization, rigor mortis, or any other factor that could alter the original shape of the fish. Therefore, the fish included in the experiment were selected from the last haul of the trip, when the transit time to port was $\sim 1$ hour. During transit, the fish were kept in seawater with ice to avoid damage or 
116 deformation. FISHSELECT measurements of blue whiting were carried out on land at the harbor 117 immediately after the fish were unloaded from the vessel. Details on the application of the standard 118 FISHSELECT methodology to blue whiting are given in Supplementary Material.

\section{Understanding SMP and diamond mesh codend size selection for blue whiting}

120

121

122

123

124

\section{Simulation of square mesh and diamond mesh selectivity}

The virtual population and the compression model obtained (see Supplementary Material) were used to simulate SMP and diamond mesh codend size selectivity. Specifically, size selection for blue whiting was simulated for meshes of varying sizes and shapes in FISHSELECT.

In trawl codends, water flow decreases as fish approach the catch-accumulation zone (Jones et al., 2008). The decreased water flow and the more open meshes in this zone favors the active escape of fish swimming here (O’Neill et al., 2003). Therefore, fish are expected to have several chances to attempt escape through the codend meshes. Multiple attempts result in a higher probability that a fish will have at least one attempt with optimal orientation towards the mesh to escape through it. Thus, size selectivity in codends can be simulated considering only optimal fish contact angle (CA) towards the mesh (Herrmann and O'Neill, 2005; Herrmann and O’Neill, 2006; Sistiaga et al., 2011; Tokaç et al., 2016). However, mesh openness is not constant in diamond mesh codends, and therefore it must be considered when simulating size selectivity (Herrmann, 2005a; O'Neill and Herrmann, 2007; Herrmann et al., 2009). For diamond meshes, mesh openness can be described by the OA (Herrmann et al., 2009).

Using the penetration model and virtual population (see Supplementary Material), we simulated the size selectivity of blue whiting through individual diamond meshes of sizes between 50 and $150 \mathrm{~mm}$ in steps of $5 \mathrm{~mm}$ and OAs between 10 and $90^{\circ}$ in steps of $5^{\circ}$. These simulations resulted in artificial "covered-codend" size selectivity datasets with fish size distributions for the fish "retained" and the fish that "escaped" through each mesh (Wileman et al., 1996). Each dataset was subsequently analyzed by fitting a logit size selection model defined by the parameters L50 and SR (Wileman et al., 1996) to the data. The results of this process consist of associated mesh size and OA and L50 values summarized in a design guide (Herrmann et al., 2009) showing L50 isocurves (lines with equal L50) dependent on mesh size and OA.

In contrast to diamond mesh codends, the mechanisms involved in the size selection through SMPs are not well understood. SMPs are usually installed at the upper panel of the extension piece of the trawl (Krag et al., 2008; Wienbeck et al., 2014; Nikolic et al., 2015) where they maintain an open mesh shape independent 

of the tension in the netting (Graham et al., 2003). Therefore, SMP size selectivity can be simulated assuming fully open square meshes. However, at this position in the trawl, SMP meshes are not located in 147 the natural swimming path of the fish (Briggs, 1992; Briggs and Robertson, 1993). Thus, in order to have a chance of escaping through the SMP meshes, most of fish need to actively change swimming direction and seek the SMP meshes (Briggs, 1992; Briggs and Robertson, 1993). Strong water flow relative to the gear in this area of the trawl makes it unlikely that every fish has multiple chances of having an optimal CA to escape through the SMP. For many blue whiting, it is likely that none of the few attempts would have an optimal CA (Fig. 1a) (i.e., perpendicular to the square mesh). For a specific mesh size, the closer the CA gets to $90^{\circ}$, the larger the projection of the mesh from the fish's perspective and, consequently, the higher probability that a larger fish can pass/squeeze itself through the mesh (Fig. 1a). However, at low CAs, the projection of the mesh becomes narrower, meaning that the size of fish that can pass through it is smaller (Fig. 1a). Therefore, when simulating SMP contact size selection, we assumed that the CA needed to be considered (size selection of the fish that actually contact the SMP and are size-selected by the meshes

\section{FIGURE 1}

164 Fig. 1. (a) Different contact angles (CAs) (ranging from 10 to $90^{\circ}$ ) for blue whiting attempting to escape through SMP meshes. The column to the right for each of the angles shows the shape of the projected mesh for the different CAs (green rectangle) and the cross-section of the largest blue whiting that would pass

167 through it (blue circle). (b) Underwater recordings from experimental trials (Cuende et al., 2020a) showing fish trajectory (red arrow) for each escape attempt with different CAs through a SMP.

To simulate SMP contact size selectivity dependent on fish CA, we first had to determine the size and shape of the mesh from the perspective of the fish. When the CA is lower than $90^{\circ}$, the projected mesh shape becomes rectangular because the mesh bars that are perpendicular with respect to the orientation of the fish

172 keep their original length, while the bars that are longitudinal with respect to the orientation of the fish shrink (Fig. 2). The length of the mesh bars that are longitudinal regarding fish orientation is given by: 
174

176

177

178

179

180

181

182

183

184

185

186

187

188

189

190

191

192

193

194

195

196

197

198

199

200

$$
p=\frac{\mathrm{m}}{2} \times \sin (\mathrm{CA})
$$

where $p$ is the projected length of the longitudinal bars of the mesh with respect to the orientation of the fish, $\frac{m}{2}$ is the mesh bar length (equal to half mesh size), and CA is the contact angle (Fig. 2).

\section{FIGURE 2}

Fig. 2. (a) Blue whiting contacting the SMP with a specific contact angle (CA). The rightmost part of the diagram shows how to calculate the mesh size projection according to the CA. $\frac{m}{2}$ is the bar length of the square meshes (half mesh size), and $p$ is the projected length of the longitudinal bars of the mesh with respect to the orientation of the fish. (b) Transformation from an original SMP mesh to the projected mesh based on the specific CA of a fish.

Using the penetration model and virtual population, we simulated the size selectivity of blue whiting through individual projected SMP meshes (rectangular meshes) resulting from CAs between 10 and $90^{\circ}$ in steps of $5^{\circ}$. The simulations were carried out for mesh sizes between 50 and $150 \mathrm{~mm}$ in steps of $5 \mathrm{~mm}$. As for the diamond meshes, a logit selection model was fitted to the size selection dataset simulated for each mesh. Results for the SMP meshes were summarized in a design guide showing L50 isocurves for different SMP mesh sizes and fish CAs.

\section{Comparison of simulated and experimental size selection}

To investigate whether the experimentally obtained size selection curves for blue whiting (Cuende et al., 2020a) could be explained by the simulated results obtained with FISHSELECT, experimental SMP and codend size selection results were compared with results simulated for different CAs and OAs, respectively. The mesh sizes for the experimental SMP and diamond mesh codend were $82.70 \mathrm{~mm}$ and $72.80 \mathrm{~mm}$, respectively (Cuende et al., 2020a). Therefore, the size selectivity for blue whiting through SMP and codend meshes of these sizes was simulated first. The size selection of a SMP with square meshes of 82.70 $\mathrm{mm}$ was simulated for CAs ranging from $10^{\circ}$ to $90^{\circ}$ in steps of $5^{\circ}$. Likewise, the size selection of a diamond mesh codend with meshes of $72.80 \mathrm{~mm}$ was simulated for OAs ranging between $10^{\circ}$ and $90^{\circ}$ in steps of $5^{\circ}$. Following the same procedure as that used in previous section, logit size selection curves were fitted to each of the simulated datasets derived from the 17 different square meshes considered and from the 17 different diamond meshes considered. 
The experimental SMP size selection curve from Cuende et al. (2020a) was plotted together with the size selection curves simulated for the square meshes derived from each CA and with the size selection curves simulated for the diamond meshes with different OAs. All fish entering the codend were assumed to have contacted the codend meshes and to have been subjected to a size-dependent escape probability through them. Therefore, we could directly compare the experimental curve for the diamond mesh codend from Cuende et al. (2020a) with the curves simulated in the present study for the meshes with different OAs. However, this direct comparison was not possible for the SMP, as experimental selection curves for the SMP in Cuende et al. (2020a) showed that only $27 \%$ of the blue whiting entering the gear in the sea trials contacted the SMP (Fig. 3a).

For a SMP, the size selectivity curve estimated based on the entire population of fish entering the gear (those that contact the device and those that do not) is known as the available SMP selectivity curve $\left(r a_{S M P}\right)$ (Fig. 3a), whereas the selectivity curve estimated based only on the fish that actually contact the device is known as the contact selectivity curve $\left(r c_{S M P}\right)$ (Millar and Fryer, 1999; Sistiaga et al., 2010) (Fig. 3b). The relationship between $r a_{S M P}$ and $r c_{S M P}$ is described by Cuende et al. (2020b) as:

$$
r a_{S M P}(l)=1-C_{S M P}+C_{S M P} \times r c_{S M P}(l)
$$

\section{FIGURE 3}

217 Fig. 3. (a) Experimental available SMP retention probability curve $\left(r a_{S M P}\right)$ (black line) with corresponding confidence intervals (dashed lines) and experimental rate (crosses). (b) Contact SMP retention probability $\left(r c_{S M P}\right)$ (black line) with corresponding confidence intervals (dashed lines).

As CAs are only relevant for the fish that actually contact the SMP, it is the experimental $r c_{S M P}$ selection curve (Fig. 3b) that needs to be explained by means of different CAs.

222 The experimental $r c_{S M P}$ and codend size selectivity curves, with their corresponding confidence intervals 223 (CIs) (Cuende et al., 2020a), were plotted together with the selection curves obtained from the 224 FISHSELECT simulations for the different rectangular meshes representing the projected square meshes and the different diamond meshes, respectively. The purpose of the comparison between the experimental and simulated curves was to determine which range of CAs and OAs could contribute to explain the size selection curves experimentally obtained for the SMP and the diamond mesh codend, respectively. The ranges selected included all simulated selection curves corresponding to the different CAs and OAs that, at 
229 least partially, were in between the CIs of the experimental $r c_{S M P}$ curve and experimental diamond codend 230 size selection curve, respectively.

231 Once the relevant ranges of CAs and OAs were identified, we estimated the contribution of each of the CAs and each of the OAs to the observed experimental SMP and codend size selection curves. The most likely combination of CAs for the SMP and OAs for the codend that could best reproduce the entire experimental selection curves were investigated for each of the cases. For this purpose, we first represented the entire experimental SMP and codend size selection by calculating L05 to L95 (length of fish with retention likelihood between $5 \%$ and $95 \%$ ) in steps of $5 \%$ for each of the curves. These values were calculated as reference points in the curves and obtained by numerical methods implemented in SELNET (Herrmann et al., 2013b). Once the experimental L05,.., L95 were obtained for SMP and codend selection curves, we tried to reproduce them based on different combinations of contributions from the different CAs and OAs by simulation in FISHSELECT. Specifically, the contributions were expressed in terms of weight factors that summed up to $100 \%$. The values of the weight factors were estimated by minimizing a penalty function. The penalty function quantified the difference in sum of squares between the experimental L05,..., L95 and the obtained one based on the FISHSELECT simulations. This method was applied using the approach described by Herrmann et al. $(2013 b, 2016)$. Application of this method resulted in a list of relative contributions of the different CAs and OAs that most accurately reproduced the experimental SMP and codend size selection curves, respectively. CAs and OAs with contributions $<0.001 \%$ were considered negligible and not included further in the analyses.

248 The contributions of the different CAs and OAs were used to create size selection curves for the SMP, 249 diamond mesh codend, and combination of the two. The curves obtained were then plotted and compared with results from the sea trials reported in Cuende et al. (2020a). For SMP size selection, $r c_{S M P}$ was converted to $r a_{S M P}$ by means of Equation 2 using the $C_{S M P}$ estimated from the sea trials. The models used to create the SMP and codend size selection curves based on the different CA and OA contributions were

253 the ones used to represent the experimental curves in each case: CGompertz for the SMP and Richard for 254 the codend (Wileman et al., 1996). Equation (3) was used to create a combined retention probability curve 255 for blue whiting based on the contributions of different CAs for the SMP selectivity and different OAs for 256 the codend selectivity:

257

$$
r_{\text {comb }}(l)=r a_{S M P}(l) \times r_{\text {codend }}(l)
$$


258 Prediction of size selectivity for different mesh size combinations of the SMP and diamond-mesh codend

260 Provided that the experimental results obtained at sea could be explained by the approach presented in the 261 previous section, predictions to explore the potential of making gear design changes were carried out in 262 FISHSELECT. Using the penetration model and virtual population (see Supplementary Material), the 263 available SMP size selection of blue whiting was simulated for mesh sizes ranging from 50 to $150 \mathrm{~mm}$ with $26410 \mathrm{~mm}$ intervals and only considering CAs that contributed to reproduction of the experimental SMP size selection curve. Likewise, codend size selection was simulated for mesh sizes ranging from 50 to $150 \mathrm{~mm}$ with $10 \mathrm{~mm}$ intervals and only considering the OAs that contributed to reproduction of the experimental curve. These simulations resulted in a "covered-codend" (Wileman et al., 1996) size selectivity dataset for each mesh size and CA or OA combination. We assumed that the contribution of the different CAs and OAs for all mesh sizes would be the same as the contributions previously estimated for the experimental SMP and codend size selection. Thus, we predicted the size selection for different SMP and codend mesh sizes by applying the contributions of the different CAs and OAs to all the SMP and codend mesh sizes simulated. The output of this procedure was a "covered-codend" dataset for each SMP and codend mesh size that considered the contribution of the different CAs and OAs, respectively. A logit size selection model was fitted to each of the resulting datasets.

Predictions of the combined size selection for blue whiting were also made for different combinations of SMP and codend mesh sizes. To explore the consequences of potential mesh size modifications in the SMP or the codend for blue whiting selectivity, we investigated how mesh size modifications would alter the selective properties of the SMP + diamond mesh codend gear used in the Basque bottom trawl fishery. Using Equation 3 and the available predicted SMP and codend size selection results, the combined size selectivity of different SMP and codend mesh sizes relevant to the Basque bottom trawl fishery were predicted. Because the regulation for the fishery requires compulsory use of a $100 \mathrm{~mm}$ SMP and a $70 \mathrm{~mm}$

282 diamond mesh size codend, we first varied the SMP mesh size from 50 to $150 \mathrm{~mm}$ in steps of $10 \mathrm{~mm}$ while keeping the codend mesh size constant at $70 \mathrm{~mm}$. We then varied the codend mesh size from 50 to $150 \mathrm{~mm}$ in $10 \mathrm{~mm}$ increments while keeping the SMP mesh size constant at $100 \mathrm{~mm}$. Blue whiting does not have a minimum conservation reference size (MCRS), but it has a minimum marketable size of 30 individuals/Kg 
287 length ratio for this species (Dorel, 1986). This size was also taken into consideration when assessing the

288

289

290

291

292

293

294

295

296

297

298

299

300

301

302

303

304

305

306

307

308

309

310

311

312

313 risk for catching or losing non-marketable and marketable blue whiting.

We then produced a series of five design guides showing L05, L25, L50, L75, and L95 for combined SMP and diamond mesh codend results; these represent sizes of blue whiting with $5 \%, 25 \%, 50 \%, 75 \%$, and $95 \%$ probability of being retained, respectively. Each design guide covered mesh sizes in the range of 50 to 150 $\mathrm{mm}$. The aim of the design guides was to show how the retention for blue whiting changes depending on the SMP and codend mesh sizes combined. These design guides provide a global picture of the selective potential of the gear and are a useful tool for identifying the best mesh size combinations for the gear.

Given that the experimental $C_{S M P}$ for blue whiting was estimated to be 0.27 (Cuende et al., 2020a), we then explored the extent to which the $r a_{S M P}$ size selectivity and combined size selectivity could be affected by increasing the $C_{S M P}$ value. We evaluated the selectivity of a $100 \mathrm{~mm}$ SMP and combined size selection of a $100 \mathrm{~mm}$ SMP and $70 \mathrm{~mm}$ codend for $C_{S M P}$ values of $0.40,0.60,0.80$, and 1.00 .

\section{Results}

\section{Morphological description of blue whiting based on FISHSELECT}

\section{Description of cross-section shapes}

The cross-section shapes of 55 blue whiting ranging from 14 to $32 \mathrm{~cm}$ in length were measured during the experimental data collection period. The analysis carried out in FISHSELECT for each of the two crosssections extracted from each individual showed that, based on $\mathrm{R}^{2}$ and AIC values, the Flexdrope and Flexellipse 1 models best fitted blue whiting cross-section 1 and 2, respectively (Table 1).

Table 1. AIC values for the different models tested for each cross-section; the model that resulted in the lowest AIC value (best model) is in bold.

\section{TABLE 1}

\section{Fall-through results and penetration model}

We obtained 26,290 experimental fall-through results for blue whiting. Based on comparisons of the fallthrough results with the different compression models tested for cross-section 1 and 2, the best agreement was found for a model that considered both cross-section 1 and cross-section 2 . For cross-section 1 , this model had $8 \%$ mean lateral compression, $0 \%$ dorsal compression, and 20\% ventral compression (Fig. 4). 
For cross-section 2, this model had $16 \%$ lateral compression, $4 \%$ dorsal compression, and $20 \%$ ventral compression (Fig. 4). The model resulted in a 97.39\% degree of agreement.

\section{FIGURE 4}

317 Fig. 4. Compression models for cross-section 1 (left) and cross-section 2 (right). Green inner curves 318 correspond to the best compression model and red outer curves correspond to no compression for each cross-section of blue whiting.

\section{Square and diamond mesh selectivity based on fish CA and mesh OA}

321

322

323

\section{Design guides for square and diamond meshes}

With the optimal penetration model defined for each species and with the ability to produce virtual populations with defined cross-sections, we produced design guides for square and diamond meshes ranging from 50 to $150 \mathrm{~mm}$ size and from 5 to $90^{\circ} \mathrm{CA}$ and $\mathrm{OA}$, respectively (Fig. 5). The square mesh design guide demonstrated that, for a given mesh size, the size selectivity of blue whiting depended greatly on the CA of the fish towards the SMP (Fig. 5a). This was especially true for the range of CAs between $10^{\circ}$ and $40^{\circ}$, where L50 increased rapidly with increasing CA. For all mesh sizes with CA $>40^{\circ}$, L50 isocurves changed into nearly vertical lines, thus L50 rose much slower with increasing CA. L50 of codend diamond meshes depended greatly on the OA, especially when OAs were between 10 and $50^{\circ}$ (Fig. 5b). For larger OAs, the influence of the angle on the L50 diminished, especially at smaller mesh sizes.

\section{FIGURE 5}

Fig. 5. Design guide for (a) square and (b) diamond meshes showing L50 isocurves as a function of mesh size $(\mathrm{mm})$, for sizes between $50 \mathrm{~mm}$ and $150 \mathrm{~mm}$, and mesh CA and OA between $10^{\circ}$ and $90^{\circ}$, respectively.

\section{Explanation and validation of the size selection curve for blue whiting based on simulations}

The size selection curves simulated for SMPs and diamond mesh codends for blue whiting based on different CAs and OAs were plotted together with the experimental $r c_{S M P}$ and codend size selection curves (Fig. 6). The results show that for both the SMP and codend, respectively, a range of CAs and OAs may contribute to the experimental size selection curves for blue whiting. Specifically, the CAs and OAs potentially involved in the selectivity process corresponded to $15^{\circ}$ to $90^{\circ} \mathrm{CAs}$ for the SMP (Fig. 6a) and $15^{\circ}$ to $50^{\circ}$ OAs for the codend (Fig. 6b). 
341

342

343

344

345

346

347

348

349

350

351

352

353

354

355

356

357

358

359

360

361

362

363

364

365

366

367

\section{FIGURE 6}

Fig. 6. Grey curves show (a) the simulated SMP selectivity for different CAs and (b) codend selectivity for different OAs from $10^{\circ}$ to $90^{\circ}$ in steps of $10^{\circ}$. Black curves depict (a) experimental $r c_{S M P}$ and (b) experimental codend size selection curve with corresponding CIs (dashed lines).

Table 2 shows the average contribution of the different CAs and OAs considered to be potentially involved in reproducing the experimental $r c_{S M P}$ and diamond mesh codend curves. Among the CAs, the relative contributions of the angles between $55^{\circ}$ and $75^{\circ}$ were below $0.001 \%$ and therefore were not considered relevant to the results for the experimental $r c_{S M P}$. In contrast, all OAs that could potentially contribute to the experimental codend selectivity curve contributed more than $0.001 \%$ and were considered relevant.

Table 2. Contribution (\%) of the considered SMP CAs and codend mesh OAs as potentially involved in reproducing experimental $r c_{S M P}$ and codend size selection curves. *: could not contribute due to no overlap with experimental selectivity curve.

\section{TABLE 2}

Using the CAs and OAs with contributions $>0.001 \%$ from Table 2, SMP, codend, and combined size selection curves were simulated. A comparison between the experimental and simulated size selectivity curves showed that the simulated SMP, codend, and combined size selection curves reproduced the experimental $r a_{S M P}$, codend, and combined size selection curves accurately (Fig. 7). These results demonstrated that SMP, diamond mesh codend, and combined size selection can be understood by the contribution of the different CAs and OAs.

\section{FIGURE 7}

Fig. 7. Experimental (black line) and simulated (yellow line) size selection curves are shown for (a) SMP, (b) codend, and (c) combined SMP and codend. Experimental 95\% CIs are shown (dashed lines).

\section{Prediction of size selectivity for different SMP and codend mesh size combinations}

Because the contributions of the CAs and OAs in Table 2 could explain the experimental SMP, codend, and combined size selection, we predicted size selection for different SMP and codend mesh combinations (Fig. 8). Results show that given the low contact probability of blue whiting with the SMP $\left(C_{S M P}=0.27\right)$, 
how much the SMP mesh size is increased) (Fig. 8a). Limited effects of changing SMP mesh size were also evident in the combined selectivity analysis (Fig. 8c), as L50 values were very similar for all mesh sizes (in between 20.15 and $21.20 \mathrm{~cm}$ ). The low contact probability between the SMP and blue whiting implies that mesh size modifications affected only the upper part of the curve, which led to a low efficiency of increasing SMP mesh size. Nevertheless, individuals of blue whiting below marketable size $(18 \mathrm{~cm})$ had high escape probability (81.85-82.20\%) through the whole predicted mesh size range (Fig. 8c). In contrast to the SMP, codend mesh size modifications affected the entire selectivity curve (Fig. 8b). Therefore, they may be a

\section{FIGURE 8}

Fig. 8. (a) Predicted $a_{S M P}$ for the mesh size range of 50 to $150 \mathrm{~mm}$ with $10 \mathrm{~mm}$ increments. (b) Predicted

ge. (c) Predicted combined retention probability of the gear by maintaining codend mesh size mandated by regulation $(70 \mathrm{~mm})$ and changing SMP mesh size for the same mesh size range. (d) Predicted combined retention probability of the gear by maintaining SMP mesh size mandated by regulation $(100 \mathrm{~mm})$ and changing codend mesh size for the same mesh size range. Thick black lines correspond to the current SMP and codend mesh sizes used by the fleet (100 and $70 \mathrm{~mm}$, respectively). Vertical dashed lines correspond to the minimum marketable size of blue whiting: $18 \mathrm{~cm}$.

Additionally, design guides for different combinations of SMP and codend mesh sizes were created (Fig. 9). Design guides for L05, L25, L50, L75, and L95 showed the length at which blue whiting had 5\%, 25\%, $50 \%, 75 \%$, and $95 \%$ probability of being retained, respectively. Specifically, the isocurves in each design guide followed different patterns; some were vertical lines with little curvature (Fig. 9a,b,c), whereas those for L75 (Fig. 9d) and L95 (Fig. 9e) showed much more curvature. At low retention probabilities $(\leq 50 \%$, Fig. 9a,b,c), gear size selection was mainly governed by codend meshes, whereas the SMP contributed to the gear size selection to a greater extent at higher retention probabilities $(\geq 75 \%$ ) (Fig. 9d,e). The low curvature of the L05, L25, and L50 isocurves was directly related to the low contact probability of blue whiting with the SMP $\left(C_{S M P}=0.27\right)$. Considering this contact factor, changing SMP mesh size will have very little effect on the overall retention probability until L73 is reached, because when retention 
397 probabilities were lower than that the fish did not contact the panel. Therefore, at L75, the contribution of 398 SMP to the gear size selection and the curvature of the isocurves becomes greater due to dependency not 399 only on codend mesh size but also on SMP mesh size. These curves become even more curled at L95 (Fig $4009 \mathrm{e})$. At this point, small changes in SMP mesh size create bigger changes in the retention length of fish 401 compared to modifications of codend mesh size.

\section{FIGURE 9}

403 Fig. 9. Design guides showing L05, L25, L50, L75, and L95 isocurves as a function of different 404 combinations of SMP and codend mesh sizes (mm) for blue whiting.

Predictions of $a_{S M P}$ and combined retention probability for different values of $C_{S M P}$ were also made (Fig. 10). As contact probability increased, the SMP retention probability for small fish decreased (Fig. 10a). Likewise, increasing contact probability led to an important improvement of the overall size selection of 408 the gear, which highlights the potential of the SMP as a size selection device (Fig. 10b).

FIGURE 10

410 Fig. 10. (a) Predicted $a_{S M P}$ retention probability assuming different values of $C_{S M P}(0.27,0.40,0.65,0.80$, 411 and 1.00). (b) Predicted combined retention curve assuming different values of $C_{S M P}$ (same as (a)). Thick 412 black lines correspond to the current SMP and codend mesh sizes used by the fleet (100 and $70 \mathrm{~mm}$, 413 respectively). Vertical dashed lines correspond to the minimum marketable size of blue whiting: $18 \mathrm{~cm}$.

\section{Discussion}

415 Different studies have reported that for SMPs, the experimental L50s are much smaller and SRs much larger 416 than theoretically expected (e.g. Alzorriz et al., 2016). The results of the present study offer an explanation 417 for the differences observed between the theoretical and practical selective performance of SMPs and show 418 that they are related to the ability of fish to contact SMPs at a more or less optimal CA. Furthermore, the 419 results of this study demonstrate that it is possible to predict size selection processes in gears composed of 420 SMPs and diamond mesh codends based on fish morphology and behaviour.

421 Previous research identified fish $\mathrm{CA}$ and orientation towards the mesh as factors that influence size 422 selection in codends and sorting grids. For example, Herrmann et al. (2013b) demonstrated how different 423 flatfish orientations towards a sorting grid could create considerable differences in the selective properties 
of the gear. Krag et al. (2014) showed that krill selectivity could be explained assuming optimal orientation and CA. Regarding SMPs, the results of the present study show that different CAs lead to different size selection for blue whiting. Based on fish and mesh morphology, we identified which CAs led to successful implicated in reproducing the experimental SMP contact size selection were between 15 and $50^{\circ}$ and 80 and $90^{\circ}$, whereas CAs between 55 and $75^{\circ}$ barely contributed to the contact size selection. Video observations made by Cuende et al. (2020a) reported that blue whiting exhibit active and erratic behavior towards SMPs, whereby they turn and swim quickly either towards the panel or the codend. Based on this behavior, we speculated that most individuals contact the SMP from less optimal angles $\left(<50^{\circ}\right)$. This may mean that the low size selection efficiency of SMPs reported in different fisheries may not be due only to low contact rates between fish and SMP meshes (Herrmann et al., 2015; Nikolic et al., 2015; Alzorriz et al., 2016; Santos et al., 2016; Brčić et al., 2018) but also to non-optimal fish CA towards the device. These differences in fish CAs could be caused by many factors, such as towing speed (which allow more or less time for fish to attempt an escape), the swimming ability of fish, or densities of fish entering the SMP section. Many of these factors are not easy to control at sea and can affect the ability of the fish to contact the SMP or to orientate well enough to have a good chance to escape through it.

Regarding codend size selection, our results for blue whiting are in line with those of previous studies in which diamond mesh codend size selection can be explained by means of mesh OAs (Sistiaga et al., 2011; Herrmann et al., 2012, 2013b; Tokaç et al., 2016, 2018). Mesh openness is driven by factors such as mesh size (Herrmann et al., 2013a), number of meshes in the circumference (Sala and Lucchetti, 2011), and the size of the catch accumulated in the codend (Wileman et al., 1996). Herein, the experimentally obtained codend size selection was entirely reproduced by the mesh OAs between 15 and $50^{\circ}$. This result emphasizes the importance of understanding the mechanisms affecting codend mesh OAs under commercial fishing conditions in order to optimize codend design and make proper size selectivity predictions.

Our results show that codend mesh OAs together with fish-SMP CAs can explain the overall size selection of a gear composed of a SMP and a diamond-mesh codend. Therefore, we were able to predict gear size selection for different combinations of SMP and codend mesh sizes for blue whiting. Even though codend meshes determine the overall size selection of the gear to a great extent due to the limited escape of blue whiting through the SMP (Cuende et al., 201920a), the design guides showed that when accounting for the fish that actually contact the SMP, small variations of its mesh size result in big changes for SMP size 
454 selection. This indicates that when SMP contact probability increases, the probability of fish contacting the

455 SMP from an optimal angle increases as well. Thus, modifying SMP mesh size can lead to greater changes

456 in the overall gear selectivity than modifying codend mesh size, which highlights the potential of SMPs as

457 size selection devices. Therefore, in addition to changes in SMP mesh size, we also considered changes in

458 SMP contact probability when making SMP size selection predictions for blue whiting. Our results showed

459 that increasing SMP contact probability without modifying its mesh size may result in great changes in gear

460 selectivity. Additionally, these results suggest that increasing SMP contact probability and favor an optimal

461 CA of fish towards the SMP meshes may be good strategies for improving size selection, especially in

462 multispecies fisheries for which increasing codend mesh size may involve less retention of valuable species.

463 In this context, research in fisheries around the world has focused on designing stimulating devices to

464 increase contact probability between fish and SMPs with different degrees of success (Glass and Wardle,

465 1995; Kim and Whang, 2010; Herrmann et al., 2015; Grimaldo et al., 2018). Regarding blue whiting,

466 Cuende et al. (2020a) showed that floating ropes attached to the lower panel beneath the SMP significantly

467 increased contact probability with the SMP and consequently the release efficiency for this species.

468 Finally, in agreement with results of previous studies reporting on the experimental suitability of SMPs for 469 blue whiting release (Briggs and Robertson, 1993; Campos and Fonseca, 2004), we found that blue whiting 470 is a species with high potential for being released by SMPs in trawl gears. Its active behaviour, which results 471 in more escape attempts, can lead to high contact rates with the SMP (Cuende et al., 2020a), thereby 472 increasing the chances of contact with an optimal CA. As blue whiting is a relevant species for fisheries 473 worldwide, both as a target and bycatch species, SMPs may be a useful selection device for the management 474 of this species in fisheries of interest, especially since the creation of the new Common Fisheries Policy 475 (Regulation EU 1380/2013).

\section{Supplementary material}

477 The following supplementary material is available at ICESJMS online. It includes a short description of the standard FISHSELECT methodology applied for collection of morphology and mesh penetrability data of

479 blue whiting. 


\section{Acknowledgements}

481 We thank the Spanish Ministry of Agriculture, Fisheries, Food and Environment for funding the research.

482 We also thank the crew of "Aketxe-Gaztelugatxe" for providing fish samples and to Iñigo Onandia for assistance during sampling process. Thanks also to TRAGSATEC for the funding that made the sea trials possible. We are also grateful to the journal editor and two anonymous reviewers that have helped to improve the quality of this manuscript. This paper is contribution $n^{\circ} 986$ from AZTI, Marine Research,

Basque Research and Technology Alliance (BRTA).

\section{References}

488

489

490

491

492

493

494

495

496

497

498

499

500

501

502

503

504

505

506

507

508

Alzorriz, N., Arregi, L., Herrmann, B., Sistiaga, M., Casey, J., and Poos, J.J. 2016. Questioning the effectiveness of technical measures implemented by the Basque bottom otter trawl fleet: Implications under the EU landing obligation. Fisheries Research 175: 116-126. doi:10.1016/j.fishres.2015.11.023.

Brčić, J., Herrmann, B., and Sala, A. 2016. Can a square-mesh panel inserted in front of the codend improve the exploitation pattern in Mediterranean bottom trawl fisheries? Fisheries Research 183: 13-18. doi:10.1016/j.fishres.2016.05.007.

Brčić, J., Herrmann, B., and Sala, A. 2018. Can a square-mesh panel inserted in front of the cod end improve size and species selectivity in Mediterranean trawl fisheries? Canadian Journal of Fisheries and Aquatic Sciences 75(5): 704-713. doi:10.1139/cjfas-2017-0123.

Briggs, R. 1992. An assessment of nets with a square mesh panel as a whiting conservation tool in the Irish Sea Nephrops fishery. Fisheries Research 13(2): 133-152. doi:https://doi.org/10.1016/01657836(92)90023-M.

Briggs, R., and Robertson, J. 1993. Square mesh panel studies in the Irish Sea Nephrops fishery. ICES CM: B20.

Broadhurst, M.K. 2000. Modifications to reduce bycatch in prawn trawls: a review and framework for development. Reviews in Fish Biology and Fisheries 10(1): 27-60. doi:https://doi.org/10.1023/A:1008936820089.

Campos, A., and Fonseca, P. 2004. The use of separator panels and square mesh windows for by-catch reduction in the crustacean trawl fishery off the Algarve (South Portugal). Fisheries Research 69(2): 147-156. doi:https://doi.org/10.1016/j.fishres.2004.05.009. 
509

510

511

512

513

514

515

516

517

518

519

520

521

522

523

524

525

526

527

528

529

530

531

532

533

534

535

536

537

Catchpole, T.L., and Revill, A.S. 2007. Gear technology in Nephrops trawl fisheries. Reviews in Fish Biology and Fisheries 18(1): 17-31. doi:10.1007/s11160-007-9061-y.

Cuende, E., Arregi, L., Herrmann, B., Sistiaga, M., and Onandia, I. $2020 a$. Stimulating release of undersized fish through a square mesh panel in the Basque otter trawl fishery. Fisheries Research 224: 105431. doi:10.1016/j.fishres.2019.105431.

Cuende, E., Arregi, L., Herrmann, B., Sistiaga, M., and Basterretxea, M. 2020b. Release efficiency and selectivity of four different square mesh panel configurations in the Basque mixed bottom trawl fishery. Scientia Marina 84(1): 39-47. doi:10.3989/scimar.04975.17A.

Dorel, D. 1986. Poissons de l'Atlantic Nord-Est. Relations Taille-Poids. IFREMER Report. pp. 165. Available from https://archimer.ifremer.fr/doc/1986/rapport-1289.pdf [accessed March 2020].

FAO. 2018. The State of World Fisheries and Aquaculture 2018-Meeting the sustainable development goals. Licence: $\quad$ CC $\quad$ BY-NC-SA 3.0 IGO. Available from http://www.fao.org/3/i9540en/I9540EN.pdf [accessed March 2020].

Frandsen, R.P., Herrmann, B., and Madsen, N. 2010. A simulation-based attempt to quantify the morphological component of size selection of Nephrops norvegicus in trawl codends. Fisheries Research 101(3): 156-167. doi:10.1016/j.fishres.2009.09.017.

Glass, C., and Wardle, C. 1995. Studies on the use of visual stimuli to control fish escape from codends. II. The effect of a black tunnel on the reaction behaviour of fish in otter trawl codends. Fisheries Research 23(1-2): 165-174. doi:https://doi.org/10.1016/0165-7836(94)00331-P.

Graham, N. 2010. Technical measures to reduce bycatch and discards in trawl fisheries. In: He P. (Ed.), Behavior of marine fishes: capture processes and conservation challenges: 237-264. doi:10.1002/9780813810966.ch10.

Graham, N., Kynoch, R., and Fryer, R. 2003. Square mesh panels in demersal trawls: further data relating haddock and whiting selectivity to panel position. Fisheries Research 62(3): 361-375. doi:https://doi.org/10.1016/S0165-7836(02)00279-5.

Grimaldo, E., Sistiaga, M., Herrmann, B., Larsen, R.B., Brinkhof, J., and Tatone, I. 2018. Improving release efficiency of cod (Gadus morhua) and haddock (Melanogrammus aeglefinus) in the Barents Sea demersal trawl fishery by stimulating escape behaviour. Canadian Journal of Fisheries and Aquatic Sciences 75(3): 402-416. doi:10.1139/cjfas-2017-0002. 
Herrmann, B. 2005a. Effect of catch size and shape on the selectivity of diamond mesh cod-ends. II. Theoretical study of haddock selection. Fisheries Research 71(1): 15-26. doi:10.1016/j.fishres.2004.08.021.

Herrmann, B. 2005b. Effect of catch size and shape on the selectivity of diamond mesh cod-ends. I. Model development. Fisheries Research 71(1): 1-13. doi:10.1016/j.fishres.2004.08.024.

Herrmann, B., and O’Neill, F.G. 2005. Theoretical study of the between-haul variation of haddock doi:10.1016/j.fishres.2005.01.022.

Herrmann, B., and O’Neill, F.G. 2006. Theoretical study of the influence of twine thickness on haddock selectivity in diamond mesh cod-ends. Fisheries Research 80(2-3): 221-229. doi:https://doi.org/10.1016/j.fishres.2006.04.008.

Herrmann, B., Krag, L.A., Frandsen, R.P., Madsen, N., Lundgren, B., and Stæhr, K.-J. 2009. Prediction of selectivity from morphological conditions: methodology and a case study on cod (Gadus morhua). Fisheries Research 97(1-2): 59-71. doi:https://doi.org/10.1016/j.fishres.2009.01.002.

Herrmann, B., Sistiaga, M., Nielsen, K.N., and Larsen, R.B. 2012. Understanding the Size Selectivity of Redfish (Sebastes spp.) in North Atlantic Trawl Codends. Journal of Northwest Atlantic Fishery Science 44: 1-13. doi:10.2960/J.v44.m680.

Herrmann, B., Wienbeck, H., Moderhak, W., Stepputtis, D., and Krag, L.A. 2013a. The influence of twine thickness, twine number and netting orientation on codend selectivity. Fisheries Research 145: 2236. doi:10.1016/j.fishres.2013.03.002.

Herrmann, B., Sistiaga, M., Larsen, R.B., Nielsen, K.N., and Grimaldo, E. 2013b. Understanding sorting grid and codend size selectivity of Greenland halibut (Reinhardtius hippoglossoides). Fisheries Research 146: 59-73. doi:10.1016/j.fishres.2013.04.004.

Herrmann, B., Wienbeck, H., Karlsen, J.D., Stepputtis, D., Dahm, E., and Moderhak, W. 2015. Understanding the release efficiency of Atlantic cod (Gadus morhua) from trawls with a square mesh panel: effects of panel area, panel position, and stimulation of escape response. ICES Journal of Marine Science 72(2): 686-696. doi:10.1093/icesjms/fsu124.

Herrmann, B., Krag, L.A., Feekings, J., and Noack, T. 2016. Understanding and Predicting Size Selection in Diamond-Mesh Cod Ends for Danish Seining: A Study Based on Sea Trials and Computer Simulations. Marine and Coastal Fisheries 8(1): 277-291. doi:10.1080/19425120.2016.1161682. 
Jones, E.G., Summerbell, K., and O'Neill, F. 2008. The influence of towing speed and fish density on the behaviour of haddock in a trawl cod-end. Fisheries Research 94(2): 166-174. doi:https://doi.org/10.1016/j.fishres.2008.06.010.

Jørgensen, T., Ingólfsson, Ó.A., Graham, N., and Isaksen, B. 2006. Size selection of cod by rigid grids—is anything gained compared to diamond mesh codends only? Fisheries Research 79(3): 337-348. doi:https://doi.org/10.1016/j.fishres.2006.01.017.

Kim, Y.H., and Whang, D.-S. 2010. An actively stimulating net panel and rope array inside a model codend to increase juvenile red seabream escapement. Fisheries Research 106(1): 71-75. doi:https://doi.org/10.1016/j.fishres.2010.07.005.

Krag, L.A., Frandsen, R.P., and Madsen, N. 2008. Evaluation of a simple means to reduce discard in the Kattegat-Skagerrak Nephrops (Nephrops norvegicus) fishery: Commercial testing of different codends and square-mesh panels. Fisheries Research 91(2-3): 175-186. doi:https://doi.org/10.1016/j.fishres.2007.11.022.

Krag, L.A., Herrmann, B., Madsen, N., and Frandsen, R.P. 2011. Size selection of haddock (Melanogrammus aeglefinus) in square mesh codends: A study based on assessment of decisive morphology for mesh penetration. Fisheries Research 110(2): 225-235. doi:10.1016/j.fishres.2011.03.009.

Krag, L.A., Herrmann, B., Iversen, S.A., Engås, A., Nordrum, S., and Krafft, B.A. 2014. Size selection of Antarctic krill (Euphausia superba) in trawls. PloS one 9(8). doi:10.1371/journal.pone.0102168.

Krag, L.A., Herrmann, B., Feekings, J., Lund, H.S., and Karlsen, J.D. 2017. Improving escape panel selectivity in Nephrops-directed fisheries by actively stimulating fish behavior. Canadian Journal of Fisheries and Aquatic Sciences 74(4): 486-493. doi:10.1139/cjfas-2015-0568.

Kvamme, C., and Isaksen, B. 2004. Total selectivity of a commercial cod trawl with and without a grid mounted: grid and codend selectivity of north-east Artic cod. Fisheries Research 68(1-3): 305318. doi:https://doi.org/10.1016/j.fishres.2003.11.011.

Millar, R.B., and Fryer, R.J. 1999. Estimating the size-selection curves of towed gears, traps, nets and hooks. Reviews in Fish Biology and Fisheries 9(1): 89-116. doi:10.1023/a:1008838220001.

Monteiro, P., Araújo, A., Erzini, K., and Castro, M. 2001. Discards of the Algarve (southern Portugal) $\begin{array}{lllll}\text { crustacean } & \text { trawl }\end{array}$ doi:https://doi.org/10.1023/A:1017575429808. 
Nikolic, N., Diméet, J., Fifas, S., Salaün, M., Ravard, D., Fauconnet, L., and Rochet, M.-J. 2015. Efficacy of selective devices in reducing discards in the Nephrops trawl fishery in the Bay of Biscay. ICES Journal of Marine Science 72(6): 1869-1881. doi:10.1093/icesjms/fsv036.

601

O'Neill, F., and Kynoch, R. 1996. The effect of cover mesh size and cod-end catch size on cod-end 602 603 selectivity. Fisheries Research 28(3): 291-303. doi:https://doi.org/10.1016/0165-7836(96)00501-

Özbilgin, H., Tosunoglu, Z., Aydin, C., Kaykaç, H., and Tokaç, A. 2005. Selectivity of standard, narrow and square mesh panel trawl codends for hake (Merluccius merluccius) and poor cod (Trisopterus minutus capelanus). Turkish Journal of Veterinary and Animal Sciences 29(4): 967-973. Available from http://journals.tubitak.gov.tr/veterinary/issues/vet-05-29-4/vet-29-4-4-0311-6.pdf [accessed April 2020].

Regulation EC 2406/1996 of 26 November 1996 laying down common marketing standards for certain fishery products. Available from https:/eur-lex.europa.eu/legalcontent/EN/TXT/PDF/?uri=CELEX:31996R2406\&from=ES [accessed March 2020].

Regulation EC 51/2006 of 22 December 2005 fixing for 2006 the fishing opportunities and associated conditions for certain fish stocks and groups of fish stocks, applicable in Community waters and, for Community vessels, in waters where catch limitations are required. Official Journal of the European UnionL 16, 148-149. Available from https://eur-lex.europa.eu/legalcontent/EN/TXT/PDF/?uri=CELEX:32006R0051\&from=EN [accessed April 2020].

Regulation EU 1380/2013 of the European Parliament and of the Council of 11 December 2013 on the Common Fisheries Policy, amending Council Regulations (EC) No 1954/2003 and (EC) No 
1224/2009 and repealing Council Regulations (EC) No 2371/2002 and (EC) No 639/2004 and Council Decision 2004/585/EC. Available from https://eur-lex.europa.eu/legalcontent/EN/TXT/PDF/?uri=CELEX:32013R1380\&from=EN [accessed April 2020].

Regulation EU 2019/1241 of the European Parliament and of the Council of 20 June 2019 on the conservation of fisheries resources and the protection of marine ecosystems through technical measures. amending Council Regulations (EC) No 1967/2006, (EC) No 1224/2009 and Regulations (EU) No 1380/2013, (EU) 2016/1139, (EU) 2018/973, (EU) 2019/472 and (EU) 2019/1022 of the European Parliament and of the Council, and repealing Council Regulations (EC) No 894/97, (EC) No 850/98, (EC) No 2549/2000, (EC) No 254/2002, (EC) No 812/2004 and (EC) No 2187/2005. PE/59/2019/REV/1. OJ L 198, 25.7.2019, p. 105-201. Available from http://data.europa.eu/eli/reg/2019/1241/oj [accessed April 2020].

Robertson, J., and Stewart, P. 1988. A comparison of size selection of haddock and whiting by square and diamond mesh codends. ICES Journal of Marine Science 44(2): 148-161. doi:https://doi.org/10.1093/icesjms/44.2.148.

Rochet, M.J., Arregi, L., Fonseca, T., Pereira, J., Pérez, N., Ruiz, J., and Valeiras, J. 2014. Demersal discard atlas for the South Western Waters. pp. 121. Available from http://www.repositorio.ieo.es/e-

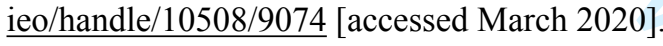

Sala, A., and Lucchetti, A. 2011. Effect of mesh size and codend circumference on selectivity in the Mediterranean demersal trawl fisheries. Fisheries Research 110(2): 252-258. doi:10.1016/j.fishres.2011.04.012.

Santos, J., Herrmann, B., Otero, P., Fernandez, J., and Pérez, N. 2016. Square mesh panels in demersal trawls: does lateral positioning enhance fish contact probability? Aquatic Living Resources 29(3): 302. doi:10.1051/alr/2016025.

Sistiaga, M., Herrmann, B., Grimaldo, E., and Larsen, R.B. 2010. Assessment of dual selection in grid based selectivity systems. Fisheries Research 105(3): 187-199. doi:10.1016/j.fishres.2010.05.006.

Sistiaga, M., Herrmann, B., Nielsen, K.N., Larsen, R.B., and Jech, J.M. 2011. Understanding limits to cod and haddock separation using size selectivity in a multispecies trawl fishery: an application of FISHSELECT. Canadian Journal of Fisheries and Aquatic Sciences 68(5): 927. doi:10.1139/f2011-017. 
Sistiaga, M., Herrmann, B., Grimaldo, E., Larsen, R.B., Olsen, L., Brinkhof, J., and Tatone, I. 2017.

658

659

660

661

662

663

664

665

666

667

668

669

670

671

672

673

674

675

676

677

678

679

680

681

682

683

684

685 Combination of a sorting grid and a square mesh panel to optimize size selection in the North-East Arctic cod (Gadus morhua) and redfish (Sebastes spp.) trawl fisheries. ICES Journal of Marine Science 75(3): 1105-1116. doi:https://doi.org/10.1093/icesjms/fsx231.

STECF. 2012. Different principles for defining selectivity under the future TM regulation (STECF-12-20). Scientific, Technical and Economic Committee for Fisheries (STECF), Joint Research Centre scientific and Policy Reports. Luxembourg: Publications Office of the European Union. Available from https://stecf.jrc.ec.europa.eu/ [accessed March 2020].

Tokaç, A., Herrmann, B., Gökçe, G., Krag, L.A., Nezhad, D.S., Lök, A., Kaykaç, H., Aydın, C., and Ulaş, A. 2016. Understanding the size selectivity of red mullet (Mullus barbatus) in Mediterranean trawl codends: A study based on fish morphology. Fisheries Research 174: 81-93. doi:10.1016/j.fishres.2015.09.002.

Tokaç, A., Herrmann, B., Gökçe, G., Ahm Krag, L., and Sadegh Nezhad, D. 2018. The influence of mesh size and shape on the size selection of European hake (Merluccius merluccius) in demersal trawl codends: An investigation based on fish morphology and simulation of mesh geometry. Scientia Marina 82(3): 147. doi:10.3989/scimar.04764.18A.

Wienbeck, H., Herrmann, B., Feekings, J.P., Stepputtis, D., and Moderhak, W. 2014. A comparative analysis of legislated and modified Baltic Sea trawl codends for simultaneously improving the size selection of cod (Gadus morhua) and plaice (Pleuronectes platessa). Fisheries Research 150: 2837. doi:https://doi.org/10.1016/j.fishres.2013.10.007.

Wileman, D.A., Ferro, R.S.T., Fonteyne, R., and Millar, R.B.E. 1996. Manual of methods of measuring the selectivity of towed fishing gears. ICES Cooperative Research Report 215. ICES, Copenhagen. pp.

126.

Available

from http://www.eurobis.org/imis?module=ref\&refid=242792\&printversion=1\&dropIMIStitle=1 [accessed March 2020].

Zuur, G., Fryer, R., Ferro, R., and Tokai, T. 2001. Modelling the size selectivities of a trawl codend and an associated square mesh panel. ICES Journal of Marine Science 58(3): 657-671. doi:https://doi.org/10.1006/jmsc.2001.1049. 


\section{Figures}

a)

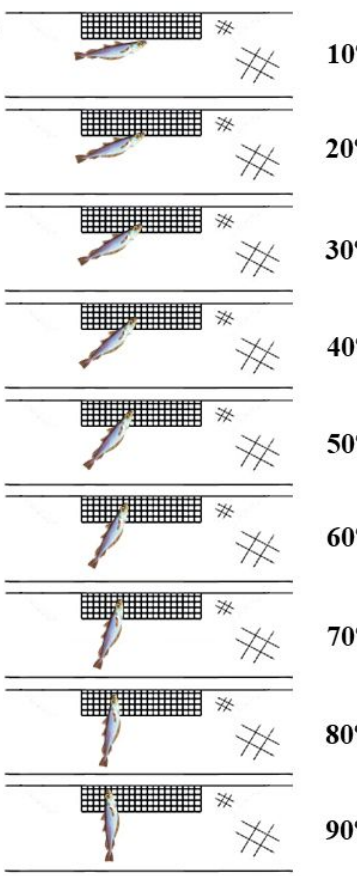

$10^{\circ}$

10

Fig. 1. (a) Different contact angles (CAs) (ranging from 10 to $90^{\circ}$ ) for blue whiting attempting to escape through SMP meshes. The column to the right of each of the angles shows the shape of the projected mesh for the different CAs (green rectangle) and the cross-section of the largest blue whiting that would pass through it (blue circle). (b) Underwater recordings from experimental trials (Cuende et al., 2020a) showing fish trajectory (red arrow) for each escape attempt with different CAs through a SMP. 
a)

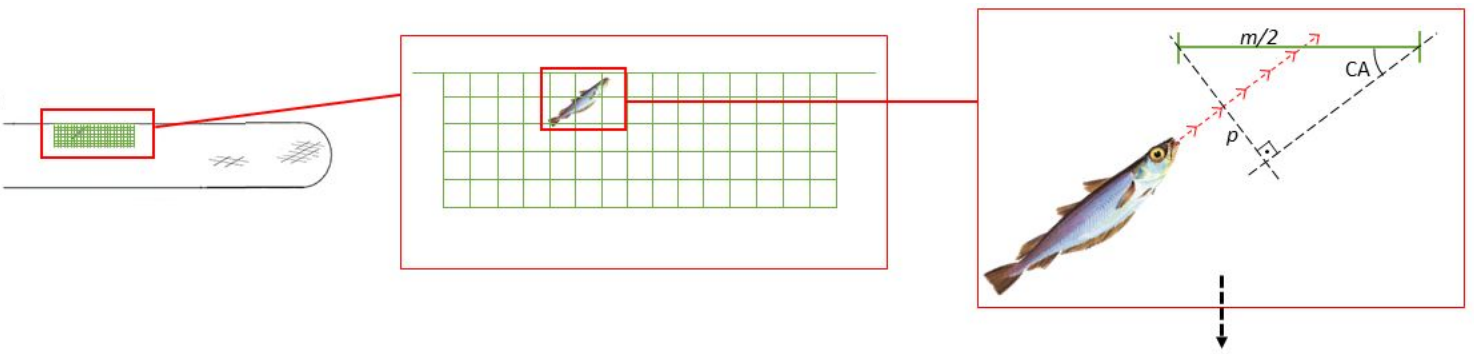

b)

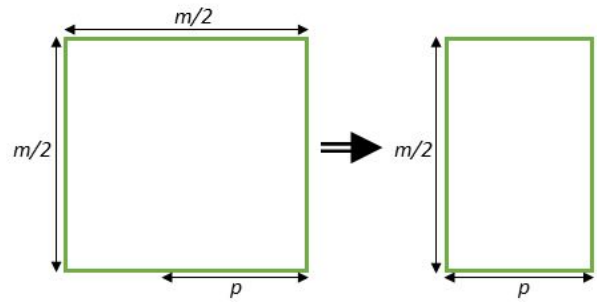

Fig. 2. (a) Blue whiting contacting the SMP with a specific contact angle (CA). The rightmost part of the diagram shows how to calculate the mesh size projection according to the CA. $\frac{m}{2}$ is the bar length of the square meshes (half mesh size), and $p$ is the projected length of the longitudinal bars of the mesh with respect to the orientation of the fish. (b) Transformation from an original SMP mesh to the projected mesh based on the specific CA of a fish. 

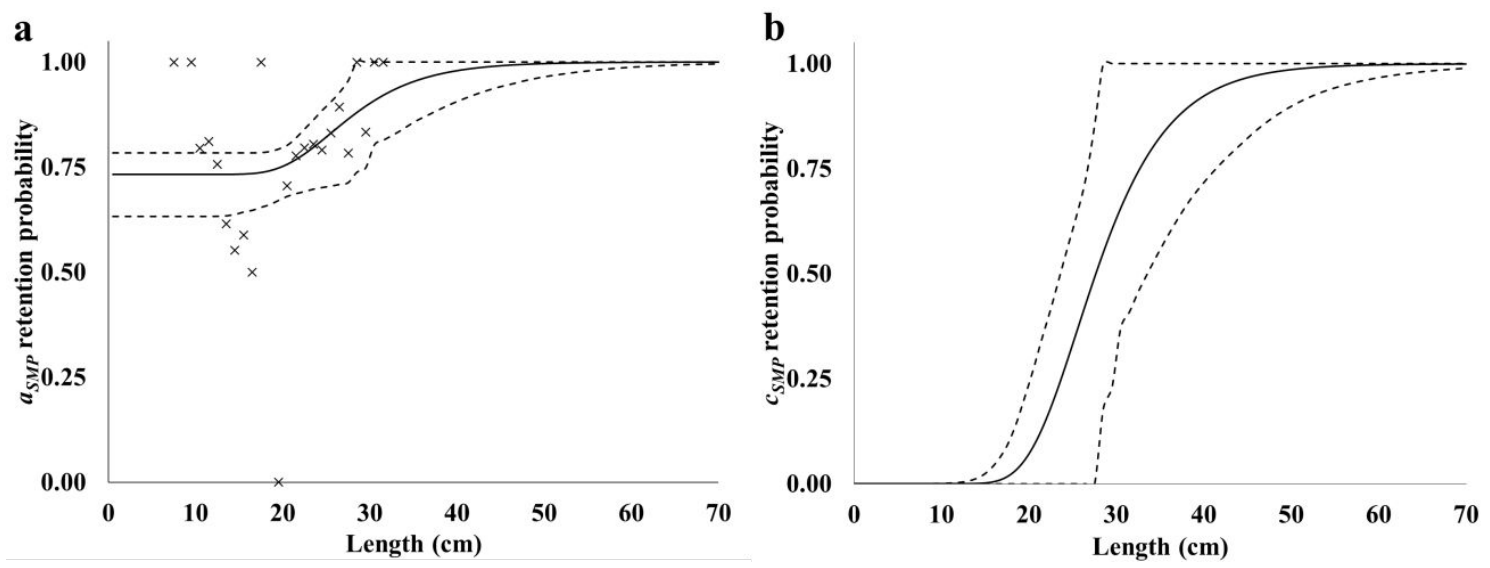

Fig. 3. (a) Experimental available SMP retention probability curve $\left(r a_{S M P}\right)$ (black line) with corresponding confidence intervals (dashed lines) and experimental rate (crosses). (b) Contact SMP retention probability $\left(r c_{S M P}\right)$ (black line) with corresponding confidence intervals (dashed lines). 


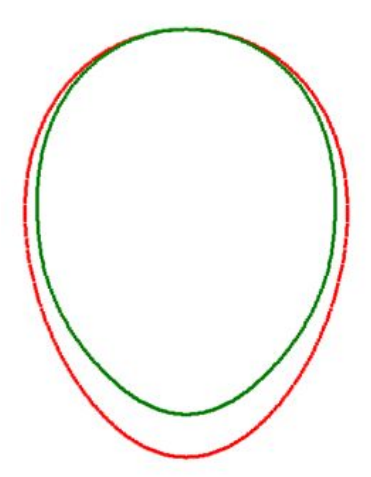

Cross-section 1

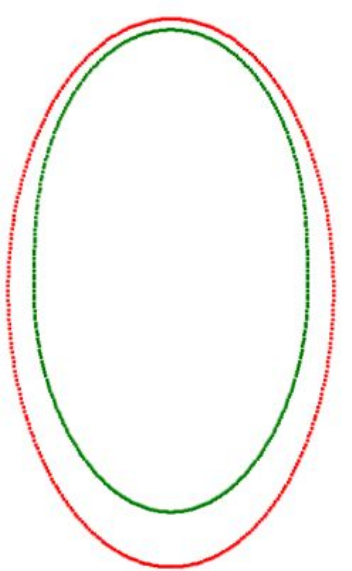

Cross-section 2

Fig. 4. Compression models for cross-section 1 (left) and cross-section 2 (right). Green inner curves correspond to the best compression model and red outer curves correspond to no compression for each cross-section of blue whiting. 

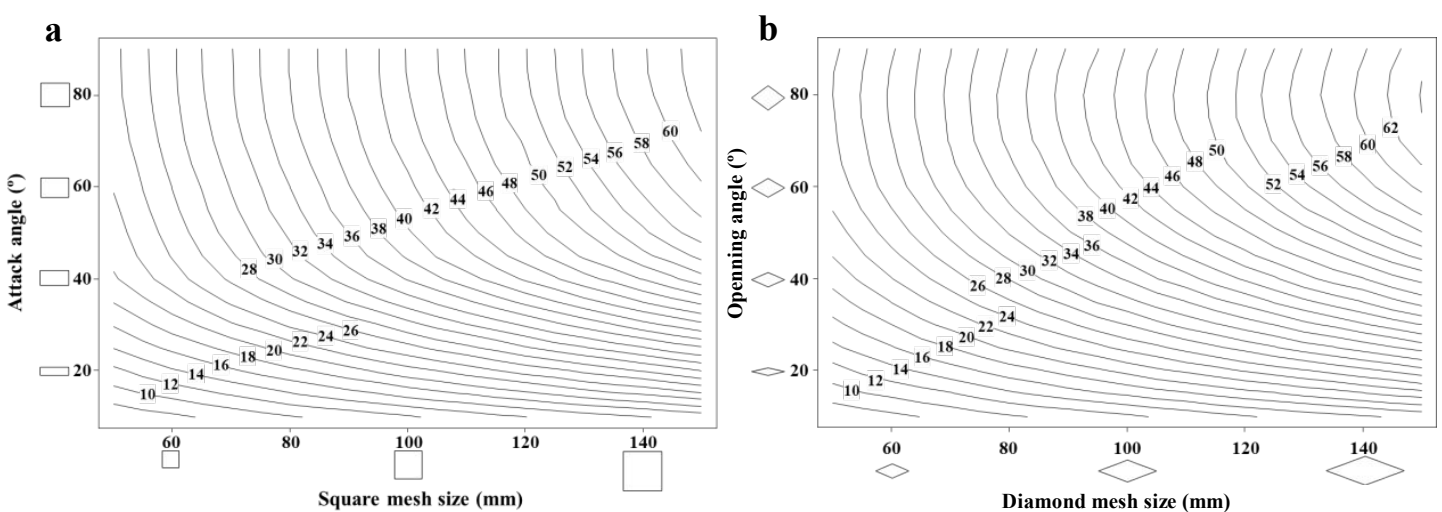

Fig. 5. Design guide for (a) square and (b) diamond meshes showing L50 isocurves as a function of mesh size $(\mathrm{mm})$, for sizes between $50 \mathrm{~mm}$ and $150 \mathrm{~mm}$, and mesh CA and OA between $10^{\circ}$ and $90^{\circ}$, respectively. 

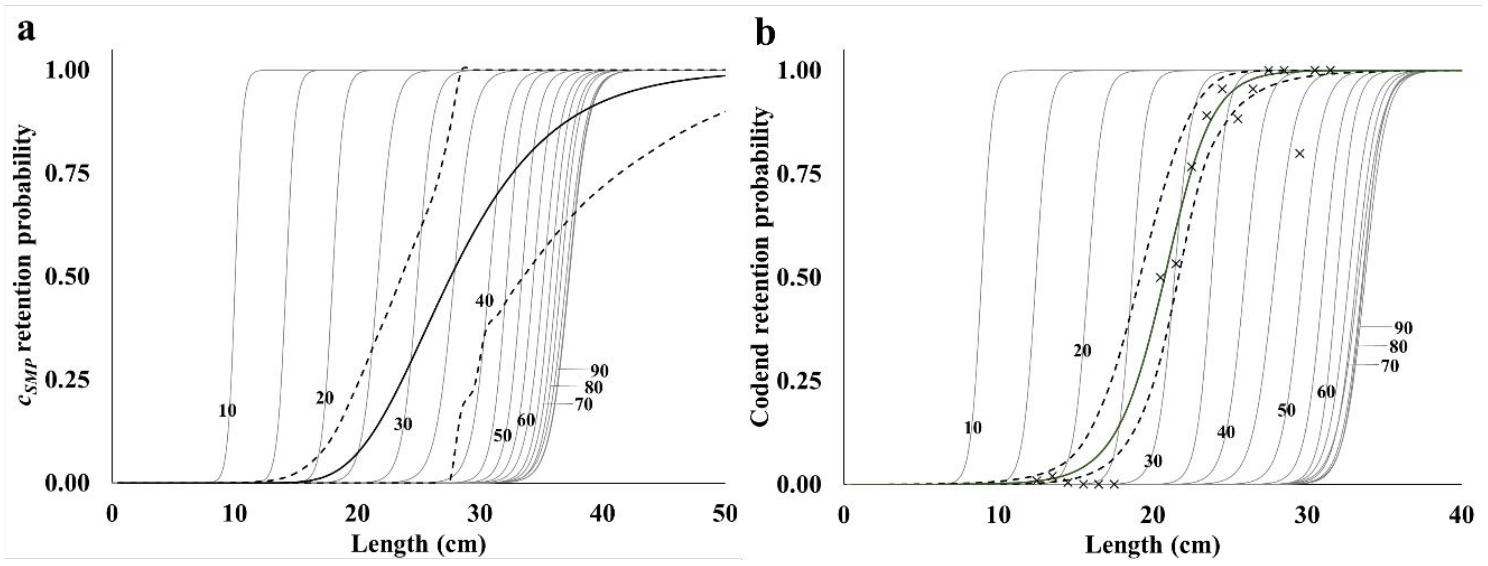

Fig. 6. Grey curves show (a) the simulated SMP selectivity for different CAs and (b) codend selectivity for different OAs from $10^{\circ}$ to $90^{\circ}$ in steps of $10^{\circ}$. Black curves depict (a) experimental $r c_{S M P}$ and (b) experimental codend size selection curve with corresponding CIs (dashed lines). 

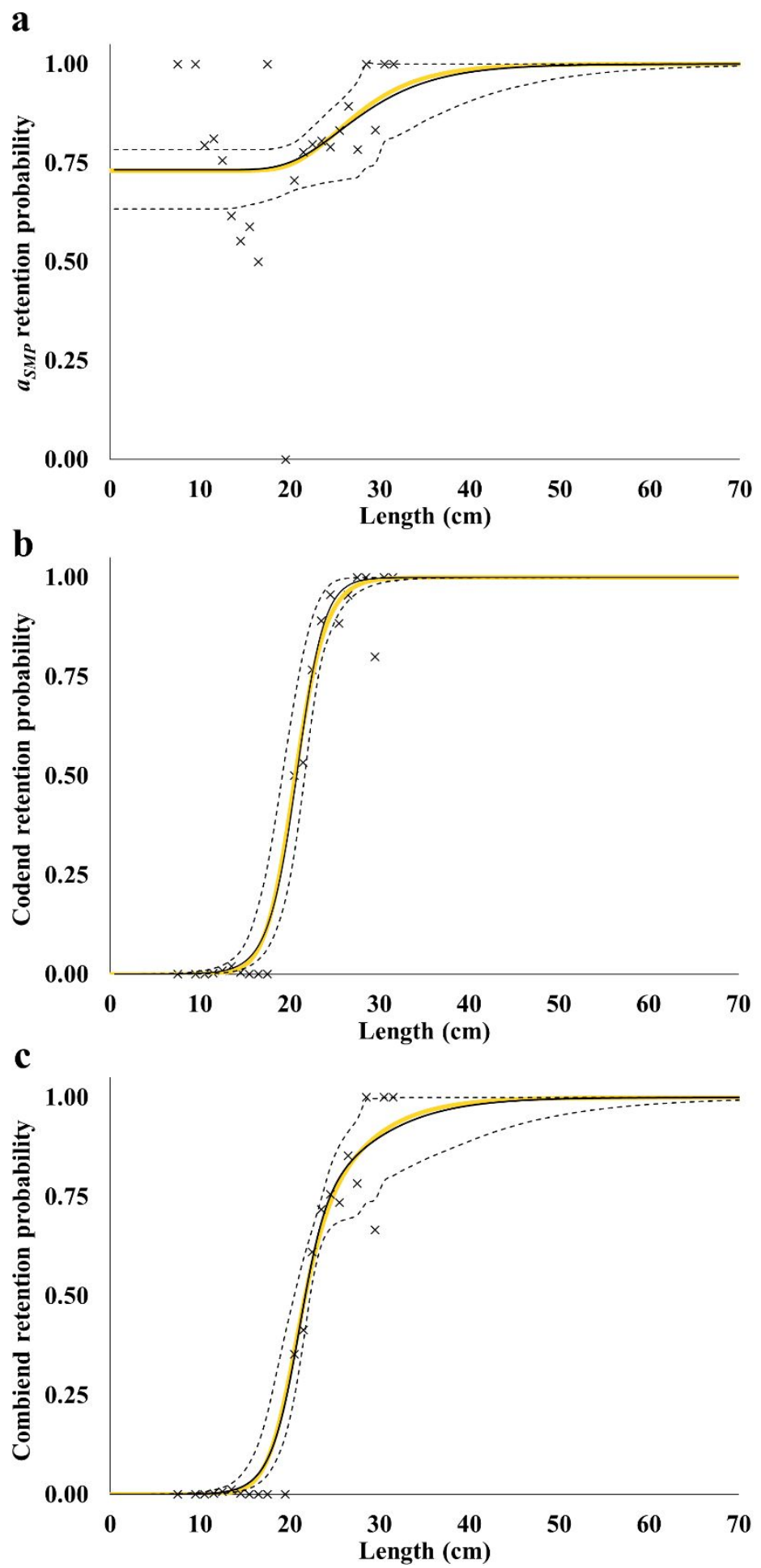

Fig. 7. Experimental (black line) and simulated (yellow line) size selection curves are shown for (a) SMP, (b) codend, and (c) combined SMP and codend. Experimental 95\% CIs are shown (dashed lines). 
a

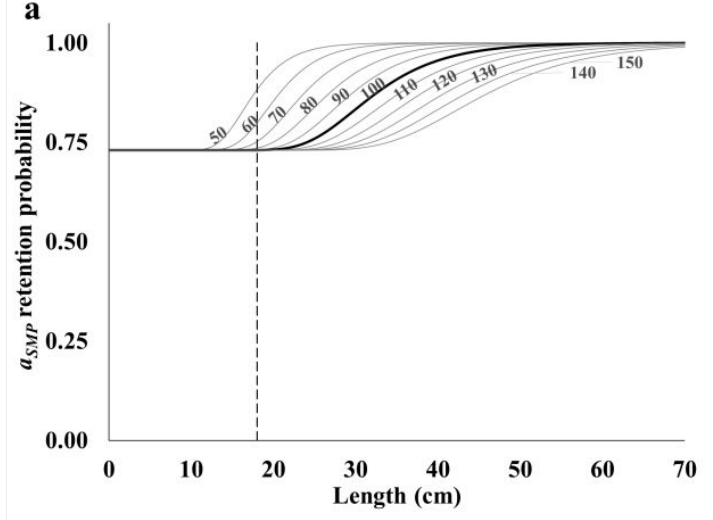

c

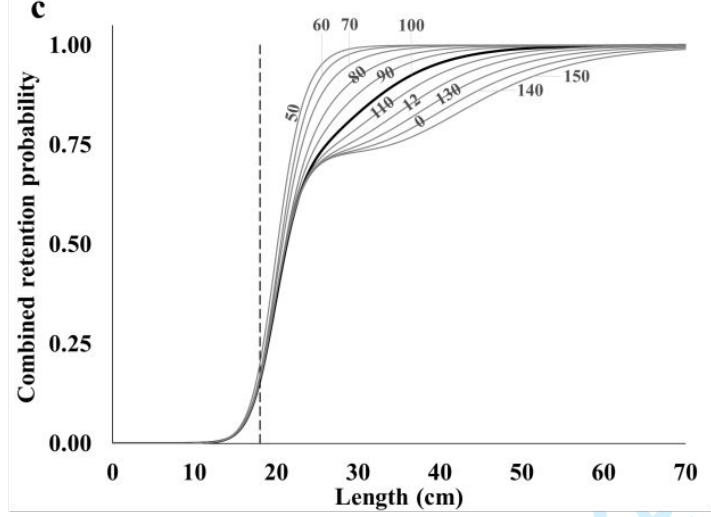

b

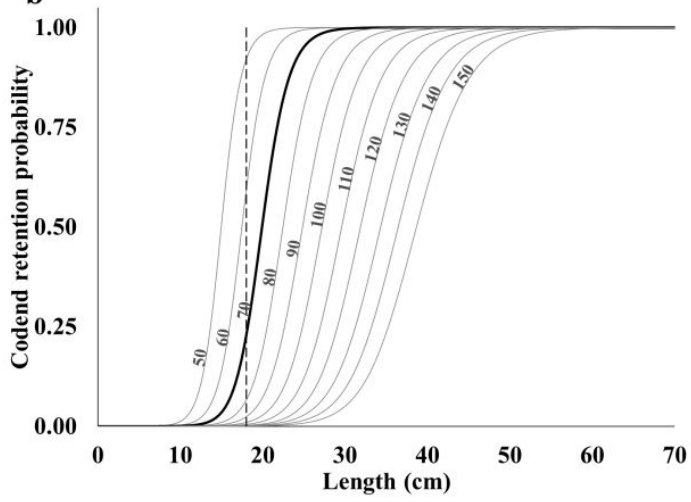

d

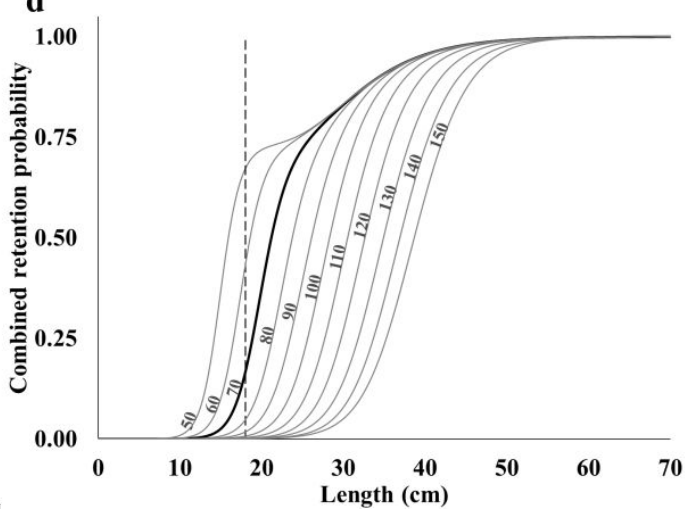

Fig. 8. (a) Predicted $a_{S M P}$ for the mesh size range of 50 to $150 \mathrm{~mm}$ with $10 \mathrm{~mm}$ increments. (b) Predicted codend retention probability for the same mesh size range. (c) Predicted combined retention probability of the gear by maintaining codend mesh size mandated by regulation $(70 \mathrm{~mm})$ and changing SMP mesh size for the same mesh size range. (d) Predicted combined retention probability of the gear by maintaining SMP mesh size mandated by regulation $(100 \mathrm{~mm})$ and changing codend mesh size for the same mesh size range. Vertical dashed lines correspond to the minimum marketable size of blue whiting: $18 \mathrm{~cm}$. 


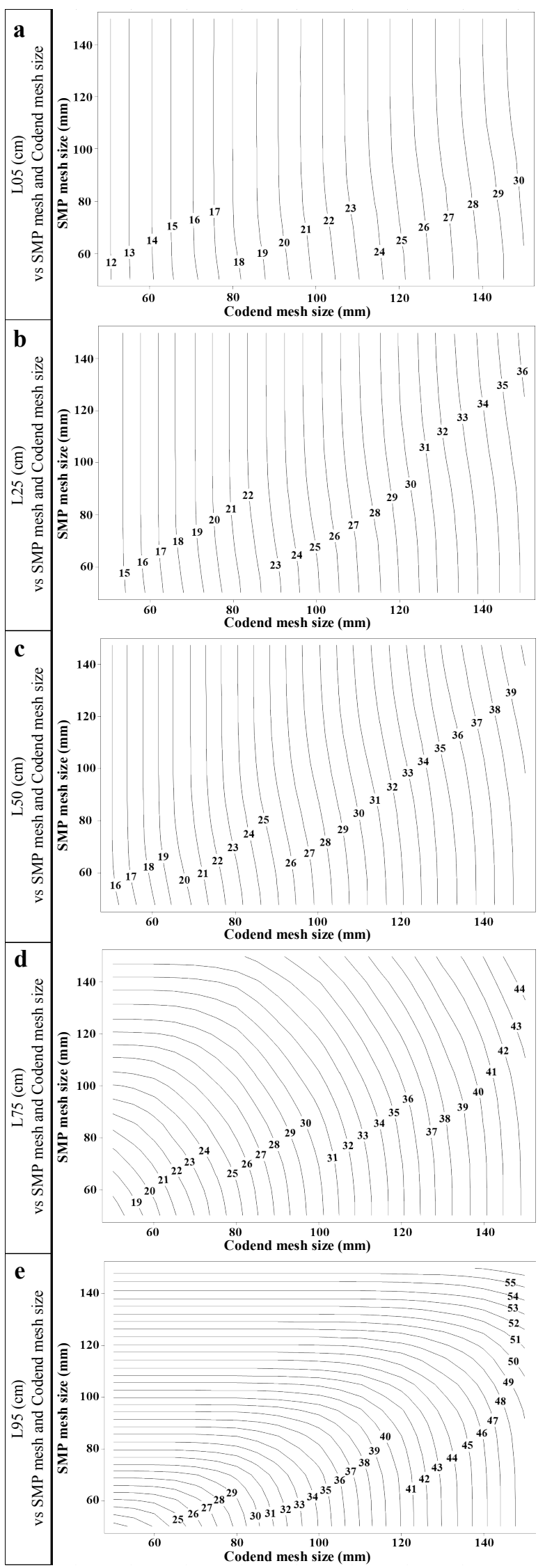

Fig. 9. Design guides showing L05, L25, L50, L75, and L95 isocurves as a function of different combinations of SMP and codend mesh sizes (mm) for blue whiting. 

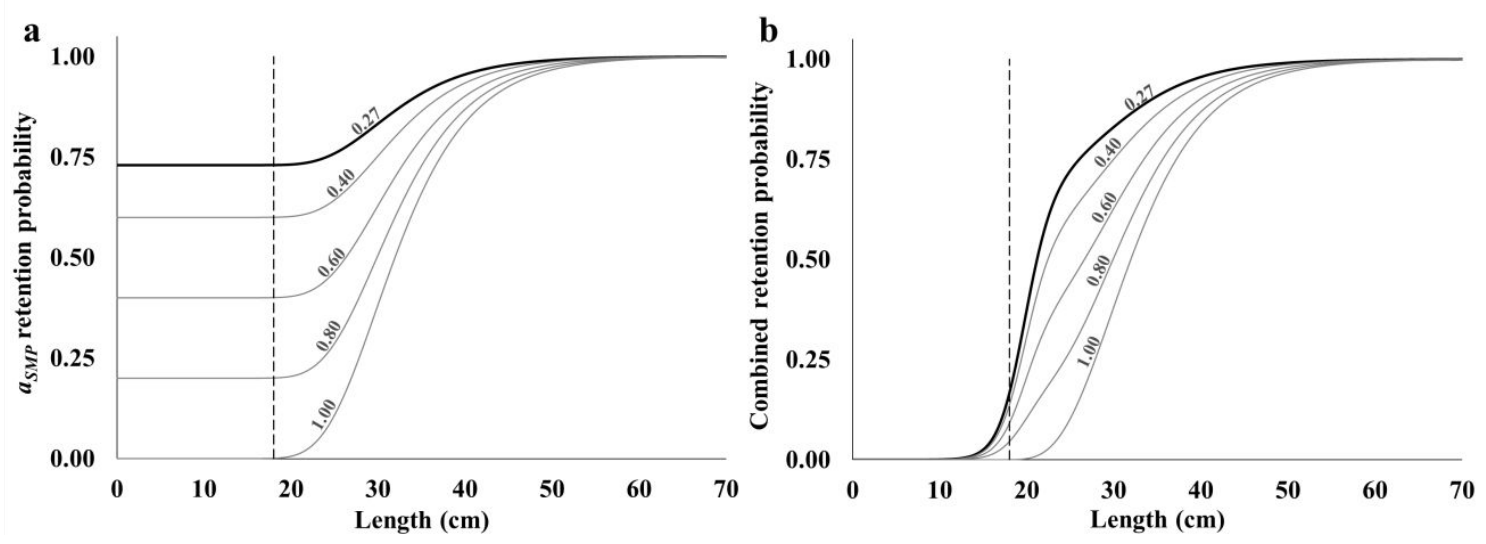

Fig. 10. (a) Predicted $a_{S M P}$ retention probability assuming different values of $C_{S M P}(0.27,0.40,0.65,0.80$, and 1.00). (b) Predicted combined retention curve assuming different values of $C_{S M P}$ (same as (a)). Thick black lines correspond to the current SMP and codend mesh sizes used by the fleet (100 and $70 \mathrm{~mm}$, respectively). Vertical dashed lines correspond to the minimum marketable size of blue whiting: $18 \mathrm{~cm}$. 


\section{Tables}

Table 1. AIC values for the different models tested for each cross-section; the model that resulted in the lowest AIC value (best model) is in bold.

\begin{tabular}{ccccccc}
\hline & & Ellipse & Flexdrope & Flexellipse 1 & Ship & Superdrope \\
\hline \multirow{2}{*}{ Cross-section 1 } & AIC & 173.07 & $\mathbf{1 4 3 . 1 3}$ & 144.53 & 157.05 & 235.04 \\
& $\mathrm{R}^{2}$ & 0.94 & $\mathbf{0 . 9 6}$ & 0.96 & 0.95 & 0.91 \\
\hline \multirow{2}{*}{ Cross-section 2 } & AIC & 200.90 & 168.32 & $\mathbf{1 6 5 . 4 4}$ & 183.66 & 226.89 \\
& $\mathrm{R}^{2}$ & 0.93 & 0.95 & $\mathbf{0 . 9 5}$ & 0.95 & 0.93 \\
\hline
\end{tabular}


Table 2. Contribution (\%) of the considered SMP CAs and codend mesh OAs as potentially involved in reproducing experimental $r c_{S M P}$ and codend size selection curves. *: could not contribute due to no overlap with experimental selectivity curve.

\begin{tabular}{|c|c|c|}
\hline \multirow[b]{2}{*}{$\mathrm{CA}$ and $\mathrm{OA}\left({ }^{\circ}\right)$} & \multicolumn{2}{|c|}{ Contribution (\%) } \\
\hline & SMP & $\begin{array}{c}\text { Diamond codend } \\
\text { meshes }\end{array}$ \\
\hline 5 & $*$ & * \\
\hline 10 & $*$ & $*$ \\
\hline 15 & 0.419 & 1.422 \\
\hline 20 & 5.040 & 7.222 \\
\hline 25 & 18.097 & 27.599 \\
\hline 30 & 18.508 & 45.361 \\
\hline 35 & 18.053 & 14.519 \\
\hline 40 & 14.217 & 0.400 \\
\hline 45 & 3.968 & 0.374 \\
\hline 50 & 0.851 & 3.104 \\
\hline 55 & 0.001 & $*$ \\
\hline 60 & 0.000 & $*$ \\
\hline 65 & 0.000 & $*$ \\
\hline 70 & 0.001 & $*$ \\
\hline 75 & 0.001 & $*$ \\
\hline 80 & 1.821 & $*$ \\
\hline 85 & 9.704 & $*$ \\
\hline 90 & 9.320 & $*$ \\
\hline
\end{tabular}

